\title{
Ecological significance of extracellular vesicles in modulating host- virus interactions during algal blooms
}

\author{
Daniella Schatz $\mathbb{D}^{1} \cdot$ Guy Schleyer ${ }^{1} \cdot$ Marius R. Saltvedt $^{2} \cdot$ Ruth-Anne Sandaa $^{2} \cdot$ Ester Feldmesser $\mathbb{D}^{3} \cdot$ Assaf Vardi $\mathbb{B}^{1}$
}

Received: 16 February 2021 / Revised: 9 May 2021 / Accepted: 14 May 2021 / Published online: 4 June 2021

(c) The Author(s) 2021. This article is published with open access

\begin{abstract}
Extracellular vesicles are produced by organisms from all kingdoms and serve a myriad of functions, many of which involve cell-cell signaling, especially during stress conditions and host-pathogen interactions. In the marine environment, communication between microorganisms can shape trophic level interactions and population succession, yet we know very little about the involvement of vesicles in these processes. In a previous study, we showed that vesicles produced during viral infection by the ecologically important model alga Emiliania huxleyi, could act as a pro-viral signal, by expediting infection and enhancing the half-life of the virus in the extracellular milieu. Here, we expand our laboratory findings and show the effect of vesicles on natural populations of E. huxleyi in a mesocosm setting. We profile the small-RNA (sRNA) cargo of vesicles that were produced by $E$. huxleyi during bloom succession, and show that vesicles applied to natural assemblages expedite viral infection and prolong the half-life of this major mortality agent of E. huxleyi. We subsequently reveal that exposure of the natural assemblage to $E$. huxleyi-derived vesicles modulates not only host-virus dynamics, but also other components of the microbial food webs, thus emphasizing the importance of extracellular vesicles to microbial interactions in the marine environment.
\end{abstract}

\section{Introduction}

The eukaryotic phytoplankter Emiliania huxleyi is a major contributor to the marine ecosystem. In temperate oceans, E. huxleyi forms massive blooms that are the basis of the marine food web and greatly influence the biogeochemical cycles of carbon and sulfur [1,2]. Annual blooms of E. huxleyi are frequently infected by a large dsDNA virus, the E. huxleyi virus (EhV) [3]. Like all other organisms, E. huxleyi produces extracellular vesicles (hereafter,

Supplementary information The online version contains supplementary material available at https://doi.org/10.1038/s41396021-01018-5.

Assaf Vardi

assaf.vardi@weizmann.ac.il

1 Department of Plant and Environmental Sciences, Weizmann Institute of Science, Rehovot, Israel

2 Department of Biological Sciences, University of Bergen, Bergen, Norway

3 Department of Life Sciences Core Facilities, Weizmann Institute of Science, Rehovot, Israel vesicles) that can serve as a mode of communication between the producing cells and specific target cells $[4,5]$. We previously showed that cultured $E$. huxleyi increases the production of vesicles during viral infection. The lipid composition of these vesicles is signifcantly different to that of their producing cells, and is composed mainly of triacylglycerols. As cargo, the vesicles carry small RNAs (sRNAs) that are predicted to target host cell cycle and lipid metabolism genes. Vesicles derived from EhV-infected cultures expedited viral infection and prolong the half-life of $\mathrm{EhV}$ in a dose dependent manner [6].

We sought to establish the ecological role of vesicles in the natural environment, and specifically, their effect on algal bloom demise and subsequent succession. To this aim, we set up a mesocosm experiment at the Marine Biological Station in Espegrend, Norway. The 23-day experiment included four mesocosm bags that contained the natural microbial assemblage. A bloom of E. huxleyi was induced (Fig. 1a) by adding nitrogen and phosphorus to the water ([7], see methods). During the course of bloom sucession, we identified three major phases: pre-bloom (days 1-9), bloom (days 10-17), and demise (days 18-23). In the demise phase, we observed an increase in the abundance of $\mathrm{EhV}$ in the water based on qPCR quantification of viral $m c p$ 

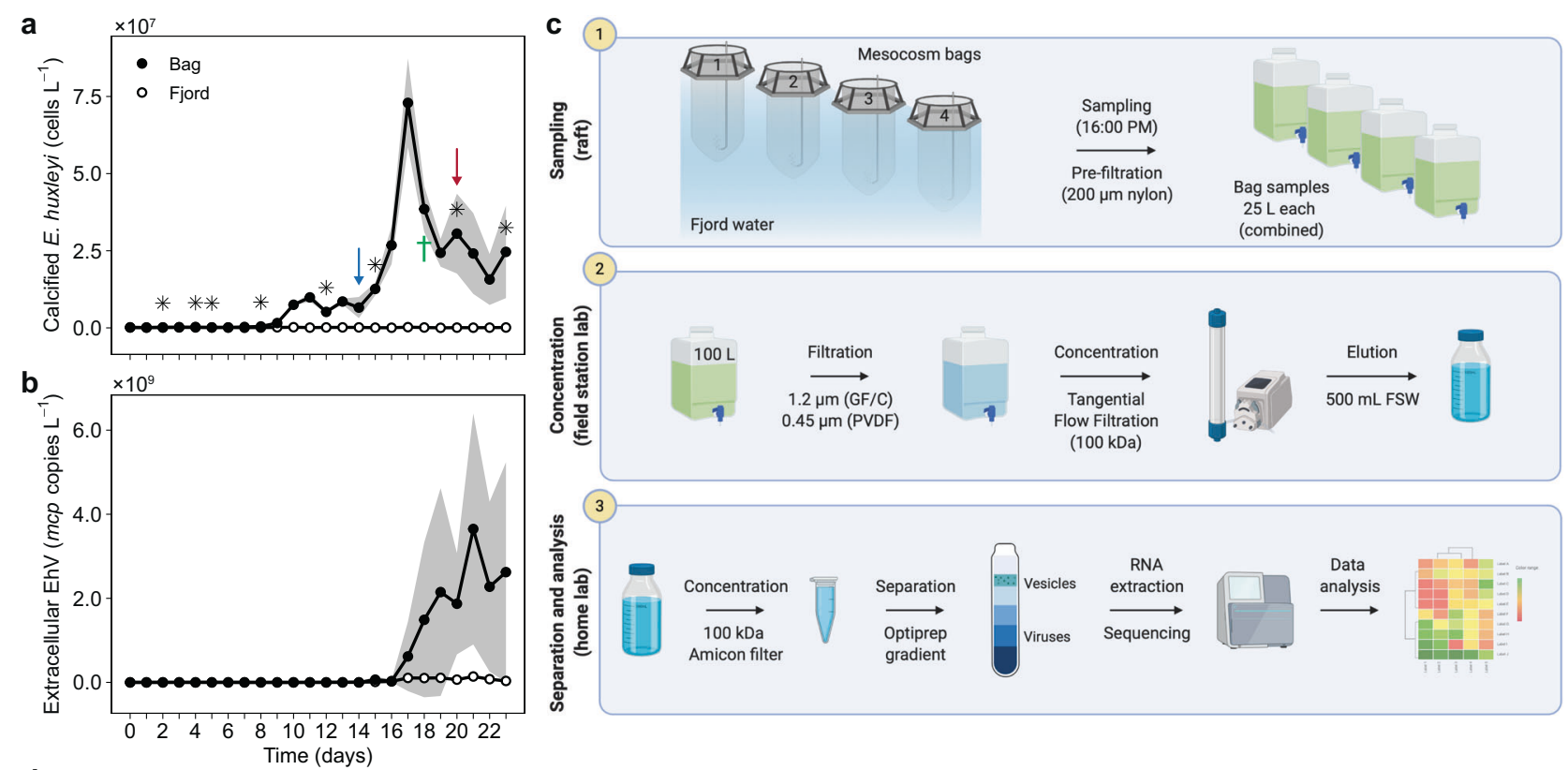

d

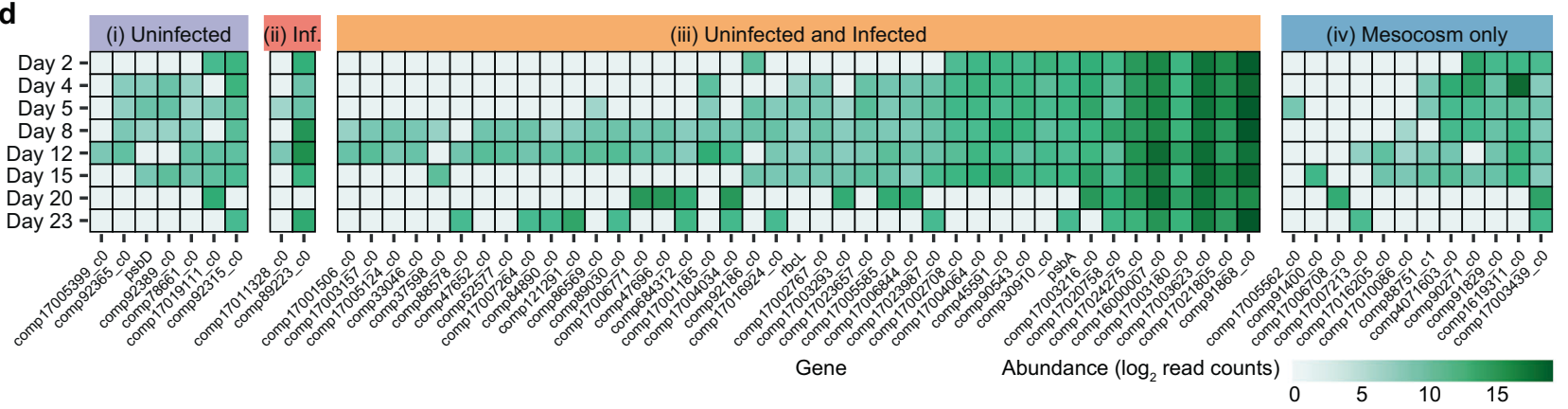

Fig. 1 Extracellular vesicles from natural $E$. huxleyi populations. A bloom of E. huxleyi was induced in a mesocosm setup at the Marine Biological Station Espegrend, Norway $\left(60^{\circ} 16^{\prime} 11 \mathrm{~N} ; 5^{\circ} 13^{\prime} 07 \mathrm{E}\right)$ in May-June 2018. Abundance of calcified E. huxleyi cells (a) was measured by flow cytometry, and EhV concentration (b) was measured by qPCR targeting the major capsid protein gene $(m c p)$. Average $\pm \mathrm{SE}$ of the four mesocosm bags are presented for (a) and of bags 2 and 4 in (b). Abundance of cells and virions was also measured in the surrounding fjord water as a "blank" control (empty circles). An asterisks indicate the times at which samples were taken for vesicle extraction; arrows indicate sampling times for the experiments presented in Fig. 2a, b; cross indicates time of sampling of EhV for the experiment presented in Fig. 2c. c Workflow for vesicle sRNA profiling. Sampling (1): 251 water samples were collected on the days marked with an asterisk in (a) from each bag using a peristaltic pump and a $200 \mu \mathrm{m}$ nylon pre-filter. Concentration (2): the water samples were combined and filtered through two subsequent filters (GF/C and $0.45 \mu \mathrm{m}$ PVDF).

(Fig. 1b), which suggests that the termination of the bloom, at least in part, was due to viral infection [8].

Throughout the bloom we collected and isolated vesicles from the mesocosm bags by concentrating them with tangential flow filtration (TFF), and enriching them by gradient separation (Fig. 1c). In a previous study we showed that the main cargo of E. huxleyi-derived vesicles is small RNA [6]. Therefore, we constructed and sequenced sRNA libraries
Samples were then concentrated to $\sim 500 \mathrm{ml}$ on a $100 \mathrm{kDa}$ TFF cartidge and stored at $4{ }^{\circ} \mathrm{C}$ in the dark. Separation and analysis (3): Once at the home lab, the samples were further concentrated on $100 \mathrm{kDa}$ Amiconultra filters, and separated on an Optiprep gradient. After speparation and cleaning, vesicles were subjected to RNase treatment to eliminate extra-vesicular RNA. sRNA within the vesicles was then extracted and sequenced. Workflow was created with BioRender.com. d Vesicles were collected from the natural assemblages at the time points indicated by an asterisk in (a) and the sRNA cargo was sequenced. sRNA sequences were aligned to E. huxleyi target genes as indicated. sRNAs that target the same genes were also found in vesicles from lab cultures of (i) uninfected E. huxleyi CCMP2090, (ii) infected cultures, (iii) Both uninfected and infected cultures or (iv) not found in vesicles from lab cultures of E. huxleyi CCMP2090. Read counts were scaled to one million reads mapped to the E. huxleyi transcriptome, $\log 2$ transformed and compared across time points.

from the vesicles isolated during the bloom. By mapping these sequences to the E. huxleyi transcriptome [9], we confirmed that some of these vesicles were produced by E. huxleyi. This was further supported by comparing the sequences to the sRNA sequences found in vesicles from lab-based cultures. We compared the potential target genes of the sRNA sequences from the natural vesicles to those of vesicles from laboratory cultures of $E$. huxleyi, and divided 
them into four categories based on the their presence in vesicles from lab cultures (Fig. 1d): (i) Seven potential target genes that were identified in cargo of vesicles from uninfected lab cultures; (ii) Two potential target genes that were identified in vesicles from lab cultures infected with EhV; (iii) 41 target genes that were identified in the cargo of vesicles from both infected and uninfected cultures and (iv) sequences of twelve genes that were identified in the cargo of natural vesicles, but were not found in vesicles from lab cultures. Most of the sRNA-target genes that we detected are found in multiple samples, which may suggest that they are ubiquitous to vesicles from E. huxleyi blooms. We also identified sRNA sequences that potentially target genes that were not targeted by sRNA in lab-based vesicles. This could be due to secretion of vesicles from $E$. huxleyi cells exposed to varying environmental conditions or during interactions of E. huxleyi with other microorganisms (e.g., bacteria) [10], that induces packaging of different sRNA molecules into vesicles. In addition, strain-specific sRNA cargo packaging can explain why these sequences were not identified in lab-based vesicles. Interestingly, despite the strong evidence for viral infection (Fig. 1b), we could only find two sequences that are related to viral infection. One of these sequences was abundant throughout the experiment, even in the pre-bloom stage.

The sRNA in vesicles may regulate specific genes in target E. huxleyi cells (Fig. 1d), and may coordinate, to some extent, their metabolic state. For example, in vesicle samples from all time points, we detected sRNA sequences that potentially regulate the E. huxleyi gene comp17003623_c0, which encodes a putative cation transport protein (Table S1). Thus, these cargo molecules may change the ability of target E. huxleyi cells to transport organic molecules and, consequently, change their metabolic profile. In addition, we found sRNA sequences that potentially regulate $h s p 70$ that is involved in stress response, including high light intensity [11]. We also detected the presence of sRNA of $r b c L$ and $p s b A$ that encode the RubisCO large subunit and the photosystem II D1 protein, respectively, suggesting a potential regulation of photosynthesis by vesicles.

In order to examine the biological effect of vesicles on infection dynamics during algal blooms, we exposed natural assemblages from the bloom to vesicles isolated from lab cultures of E. huxleyi CCMP2090 at a ratio of $\sim 500$ vesicles per E. huxleyi cell, which is the estimated ratio in lab cultures at the end of infection [6]. When applied to microbial communities from the early bloom phase (day 14), the vesicles had little to no effect on the growth of major phytoplankton groups (Fig. 2a). We observed a small reduction in bacterial abundance $48 \mathrm{~h}$ after vesicle treatment, which suggests that the bacteria do not benefit from the vesicles and do not use them as a source for nutrients, as suggested for vesicles of Prochlorococcus [12]. Interestingly, treatment of the natural population taken from $E$. huxleyi demise phase (day 20, Fig. 2b), when EhV was clearly present in the population (Fig. 1b), led to a significant reduction in the abundance of nanophytoplankton, a group that includes E. huxleyi. This was accompanied by an elevated EhV-like particle abundance as compared to the control populations that were not exposed to vesicles (Fig. 2b). We suggest that extracellular vesicles expedite viral infection not only in E. huxleyi cultures but also during bloom demise. We did not observe an effect of vesicles on the calcified $E$. huxleyi population which could be due to simultaneous growth of virus-resistant strains [13] or induction of a non-lytic infection stage [8, 14]. This experimental setup enabled us to examine the effect of vesicles from E. huxleyi on other members of the microbial food web. Indeed, we observed an elevated abundance of Synechococcus in the vesicle-treated samples, compared to those that were not exposed to vesicles. This result accentuates the effect of $E$. huxleyi-produced vesicles, not only on E. huxleyi itself, but also on other photosynthetic microorganisms in the natural assemblage. We propose that E. huxleyi and Synechococcus compete for resources, and when vesicles expedite the viral infection of E. huxleyi, Synechococcus can grow faster. An alternative scenario can be that allelopathic interactions between E. huxleyi and Synechococcus may suppress Synechococcus growth during the E. huxleyi bloom. When vesicles are plentiful, viral infection of $E$. huxleyi is expedited and the allelopathic pressure is potentially alleviated from Synechococcus. This result enables the expansion of the impact of the viral shunt during algal bloom demise from heterotrophic [15] to photosynthetic bacteria.

We previously showed that under laboratory conditions, incubating $\mathrm{EhV}$ virions with vesicles derived from infected cultures led to a prolonged half-life of the viruses [6]. To test the ecological significance of this phenomenon, we incubated natural EhV with vesicles derived from both infected and uninfected lab cultures of $E$. huxleyi under natural light and temperature conditions, and examined the decay by assessing the loss of infectivity over time (Fig. 2c). Vesicles derived from infected E. huxleyi cultures led to a prolonged half-life of natural $\mathrm{EhV}$, in which we observed a $50 \%$ decay in $\sim 60 \mathrm{~h}$, as compared to $\sim 30 \mathrm{~h}$ in the untreated samples. Since $\mathrm{EhV}$ is a specialized virus that can only infect $E$. huxleyi, this effect can have a major consequence to the survival of infective virions in the environment, where they are exposed to UV and other damaging conditions [16, 17]. Interestingly, vesicles from uninfected lab cultures of E. huxleyi led to rapid decay of EhV infectivity. This profound effect resulted in a complete loss of infectivity after $48 \mathrm{~h}$ of incubation with $\mathrm{EhV}$ virions (Fig. 2c, see "Methods" section). 


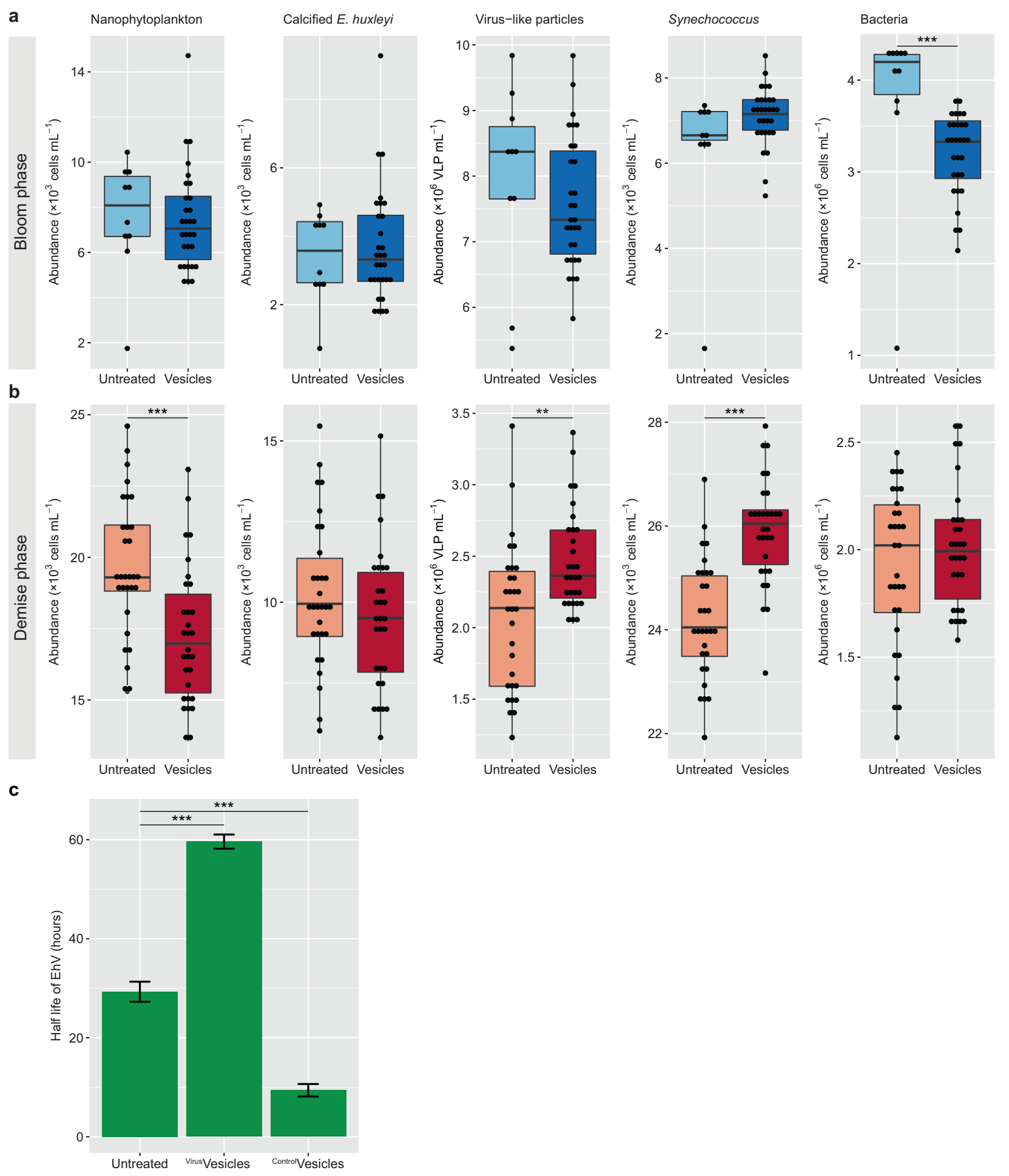

Taken together, we propose that in the natural environment, uninfected $E$. huxleyi cells protect themselves by secreting vesicles that reduce the half-life of EhV particles (Fig. 2c). However, once infection of the E. huxleyi population is initiated, a cascade of cellular events ultimately leads to expedited viral infection (Fig. 2b), concomitant with elevation of the half-life of the virions in the environment (Fig. 2c). This might have an effect on other phytoplankton species, such as Synechococcus, thus affecting the succession of species in the marine environment. We propose that communication via extracellular vesicles during microbial interactions in algal blooms may have a profound effect on the growth and composition of the associated marine microbial food webs. 
Fig. 2 Extracellular vesicles modulate viral infection of $E$. huxleyi and prolong the half-life of $\mathbf{E h V}$ in natural assemblages. Vesicles derived from lab cultures of E. huxleyi CCMP2090 were incubated with natural microbial populations from (a) the early bloom phase (day 14, blue arrow in Fig. 1a) or (b) demise phase (day 20, red arrow in Fig. 1a). Abundance of nanophytoplankton (including calcified and non-calcified E. huxleyi), calcified E. huxleyi, EhV-like particles, Synechococcus, and bacteria was measured by flow cytometry $48 \mathrm{~h}$ post-treatment. In (a), significant difference between the treated and untreated populations was observed only for bacteria $(* * * p$ value $=$ 0.001 ). For untreated $n=10$, for vesicle-treated $n=30$. In (b), significant reduction in nanophytoplankton abundance $(* * * p$ value $=$ 0.0003), concomitant with elevation in EhV-like particle count $(* * p$ value $=0.009)$ and Synechococcus abundance $(* * * p$ value $=$ $1.03 \times 10^{-7}$ ) was observed. For both treated and untreated $n=30$. At least 10,000 events were counted for each gate. In (a) and (b), $p$ value was calculated using two tailed $t$ test with equal variance. $\mathbf{c}$ Half-life of infectious EhV from the mesocosm bags, measured by the most probable number (MPN) method. EhV was sampled from the bags during the demise phase of the bloom (day 18, green cross in Fig. 1a). Vesicles from infected ( ${ }^{\text {Virus }}$ Vesicles) or uninfected ( ${ }^{\mathrm{Control}}$ Vesicles) lab cultures of E. huxleyi CCMP2090 were added to natural EhV at a ratio of 10 vesicles per EhV-like particle. For the ${ }^{\text {Control }}$ vesicle treatment, the decay was so fast we could not detect infectivity in more than one time point. Therefore, the minimum detectable infectivity values were used in the subsequent time points in order to calculate the maximum possible half-life. Average $\pm \mathrm{SE}$ is presented. $* * * p$ value $<0.001$ for each treatment compared to the untreated control, using ANOVA with Dunnett's post-hoc test, $n=3$.

\section{Materials and methods}

\section{Mesocosm setup}

The mesocosm experiment AQUACOSM VIMS-Ehux was carried out between $24^{\text {th }}$ May (day 0 ) and $16^{\text {th }}$ June (day 23) 2018 in Raunefjorden at the Marine Biological Station Espegrend, Norway $\left(60^{\circ} 16^{\prime} 11 \mathrm{~N} ; 5^{\circ} 13^{\prime} 07 \mathrm{E}\right)$ as previously described [7]. Four light-transparent enclosure bags were filled with surrounding fjord water (day -1 ; pumped from $5 \mathrm{~m}$ depth), and continuously mixed by aeration (from day 0 onwards). Each bag was supplemented with nutrients at a nitrogen to phosphorous ratio of $16: 1\left(1.6 \mu \mathrm{M} \mathrm{NaNO}{ }_{3}\right.$ and $0.1 \mu \mathrm{M} \mathrm{KH}_{2} \mathrm{PO}_{4}$ final concentration) on days $0-5$ and 14-17, whereas on days 6,7 , and 13 only nitrogen was added. Nutrient concentrations were measured daily [18].

\section{Enumeration of phytoplankton cells by flow cytometry}

For E. huxleyi enumeration by flow cytometry, water samples were collected in $50 \mathrm{~mL}$ tubes from $\sim 1 \mathrm{~m}$ depth. Water samples were pre-filtered using $40 \mu \mathrm{m}$ cell strainers and immediately analyzed with an Eclipse iCyt flow cytometer (Sony Biotechology, Champaign, IL, USA) as previously described [19]. A total volume of $300 \mu \mathrm{l}$ with a flow rate of $150 \mu 1 \mathrm{~min}^{-1}$ was analyzed. A threshold was applied on the forward scatter to reduce background noise. Four groups of phytoplankton populations were identified in distinct gates by plotting the autofluorescence of chlorophyll (em: 663-737 nm) versus phycoerythrin (em: $570-620 \mathrm{~nm}$ ) and side scatter: calcified E. huxleyi (high chlorophyll and high side scatter), Synechococcus (high phycoerythrin), nanophytoplankton including calcified and non-calcified $E$. huxleyi (high chlorophyll and phycoerythrin), and picophytoplankton (low chlorophyll and low phycoerythrin) [20]. See Fig. S1 for further details of gating strategy.

\section{Enumeration of EhV-like particles and bacteria by flow cytometry}

For EhV and bacteria counts, $200 \mu \mathrm{l}$ of sample were fixed a final concentration of $0.5 \%$ glutaraldehyde for one hour at 4 ${ }^{\circ} \mathrm{C}$ and flash frozen in liquid nitrogen. For analysis, they were thawed and stained with SYBR gold (Invitrogen, Carlsbad, CA, USA) that was diluted $1: 10,000$ in $0.2 \mu \mathrm{m}$ filtered TE buffer (10:1 mM Tris:EDTA, $\mathrm{pH}$ 8), incubated for $20 \mathrm{~min}$ at $80^{\circ} \mathrm{C}$ and cooled to room temperature [21]. Bacteria and EhV-like particles were counted and analyzed using an Eclipse iCyt flow cytometer (ex: $488 \mathrm{~nm}$, em: $500-550 \mathrm{~nm}$ ), and identified by comparing to reference samples containing fixed EhV201 and bacteria from lab cultures. EhV gating was very stringent in order to minimize the misidentification of other large viruses such as Micromonas pusilla virus $(\mathrm{MpV})$ in the samples (see Fig. S2 for further details of gating strategy for EhV counts).

\section{Enumeration of extracellular EhV by qPCR}

Water samples (1-21) were sequentially filtered by vacuum through polycarbonate filters with a pore size of $20 \mu \mathrm{m}$ ( $47 \mathrm{~mm}$; Sterlitech, Kent, WA, US), then $2 \mu \mathrm{m}$ (Isopore, $47 \mathrm{~mm}$; Merck Millipore, Cork, Ireland), and finally $0.22 \mu \mathrm{m}$ (Isopore, $47 \mathrm{~mm}$; Merck Millipore). Filters were immediately flash-frozen in liquid nitrogen and stored at $-80^{\circ} \mathrm{C}$ until further processing. DNA was extracted from the $0.22 \mu \mathrm{m}$ filters using the DNeasy PowerWater kit (Qiagen, Hilden, Germany) according to the manufacturer's instructions. Each sample was diluted 100 times, and $1 \mu \mathrm{l}$ was then used for qPCR analysis. EhV abundance was determined by qPCR for the major capsid protein $(\mathrm{mcp}$ ) gene [22] using the following primers: 5'-acgcaccctcaa tgtatggaagg- $3^{\prime}(\mathrm{mcp} 1 \mathrm{~F}[23]$,) and 5'-rtscrgccaactcagcagtcgt3' (mcp94Rv; Mayers, K. et al., unpublished). All reactions were carried out in technical triplicates. For all reactions, Platinum SYBR Green qPCR SuperMix-UDG with ROX (Invitrogen) was used as described by the manufacturer. Reactions were performed on a QuantStudio 5 Real-Time PCR System equipped with the QuantStudio Design and Analysis Software version 1.5.1 (Applied Biosystems, 
Foster City, CA, USA) as follows: $50{ }^{\circ} \mathrm{C}$ for $2 \mathrm{~min}, 95^{\circ} \mathrm{C}$ for $5 \mathrm{~min}, 40$ cycles of $95^{\circ} \mathrm{C}$ for $15 \mathrm{~s}$, and $60^{\circ} \mathrm{C}$ for $30 \mathrm{~s}$. Results were calibrated against serial dilutions of EhV201 DNA at known concentrations, enabling exact enumeration of viruses. Samples showing multiple peaks in melting curve analysis or peaks that were not corresponding to the standard curves were omitted.

\section{Vesicle concentration and separation}

\section{Lab samples}

E. huxleyi CCMP2090 was grown in 201 filtered sea water (FSW) supplemented with $\mathrm{K} / 2$ nutrient mix at $18{ }^{\circ} \mathrm{C}, 16: 8 \mathrm{~h}$ light:dark cycle, $100 \mu \mathrm{mol}$ photons $\mathrm{m}^{-2} \mathrm{~s}^{-1}$. Uninfected cultures were grown to $\sim 10^{6}$ cells $\mathrm{ml}^{-1}$. Infected cultures were inoculated with EhV201 at a multiplicity of infection (MOI) of $\sim 1: 1$ plaque forming unit (pfu) per cell and incubated under normal growth conditions for $120 \mathrm{~h}$, at which time the culture had cleared. The entire 201 volume was then filtered through a GF/C filter (Whatman, Maidstone, United Kingdom) followed by an $0.45 \mu \mathrm{m}$ PVDF filter (Durapore, Merck Millipore) to eliminate cells and cellular debris.

\section{Mesocosm samples}

On days $2,4,5,8,12,15,18$, and 23 we collected 251 from bags 1-4 and combined them to produce one sample of 1001 for each sampling time. The samples were pre-filtered using a $200 \mu \mathrm{m}$ nylon mesh, and then filtered through a GF/C filter (Whatman) followed by an $0.45 \mu \mathrm{m}$ PVDF filter (Durapore, Merck Millipore) to eliminate cells and cellular debris.

\section{Particle concentration}

Particles in the flow-through from the filtration stage were concentrated on a $100 \mathrm{kDa}$ tangential flow filter (Spectrumlabs, Repligen, Waltham, Massachusetts, USA) to a final volume of $\sim 500 \mathrm{ml}$. At this stage, mesocosm samples were stored in the dark at $+4{ }^{\circ} \mathrm{C}$ and shipped back to the home lab. All samples were further concentrated to a final volume of $1-2 \mathrm{ml}$ using $100 \mathrm{kDa}$ Amicon-ultra filters (Merck Millipore).

\section{Vesicle separation}

Vesicles were separated from other particles (including viruses) using an 18-35\% OptiPrep gradient (MilliporeSigma, St. Louis, Missouri, USA). Gradients were centrifuged in an ultracentrifuge for $12 \mathrm{~h}$ at $200,000 \times g$.
Fractions $(0.5 \mathrm{ml})$ were collected from the top of the gradient and the fraction material was cleaned by washing three times and resuspended in $0.02 \mu \mathrm{m}$-filtered FSW using 100 $\mathrm{kDa}$ Amicon-ultra filters (Merck Millipore). Vesicles were detected in fractions with densities of $1.05-1.07 \mathrm{~g} \mathrm{ml}^{-1}$ (fractions 3-5 from the top).

Vesicle concentration in samples from lab cultures was measured by NTA using the NanoSight NS300 instrument (Malvern Instruments, Malvern, UK) equipped with a $488 \mathrm{~nm}$ laser module and NTA V3.2 software. Samples were diluted so that each field of view contained 20-100 particles. Three $60 \mathrm{~s}$ videos were recorded for each biological replicate, representing different fields of view. All the videos for a given experiment were processed using identical settings (screen gain of one and detection threshold of five).

\section{RNA extraction and sequencing}

In order to eliminate RNA molecules that are not packed into vesicles, we subjected vesicle samples to RNase treatment prior to RNA extraction. Samples were incubated for $60 \mathrm{~min}$ at $37^{\circ} \mathrm{C}$ with $10 \mathrm{pg} \mu \mathrm{l}^{-1}$ of RNase A (Bio Basic, Toronto, Canada). RNase activity was inactivated by adding 100 unites of Protector RNase Inhibitor (Roche, Basel, Switzerland). Total RNA (including RNA from $~ 18$ nucleotides or more) was extracted using the miRNeasy kit according to the manufacturer's instructions (Qiagen). Libraries were prepared using the TruSeq Small RNA Library kit (Illumina, San Diego, CA, USA), according to the manufacturer's protocol. Each sample was indexed twice with the same index, one with polynucleotide kinase I treatment (according to manufacturer's instructions, NEB, Ipswich, Massachusetts, USA) and one without. After 15 cycles of PCR amplification, libraries were cleaned with the QIAquick PCR Purification Kit according to the manufacturer's instructions (Qiagen). Libraries were sequenced on the NextSeq platform (Illumina).

\section{sRNA bioinformatics analysis}

Low-quality read ends were trimmed and adaptors were removed using the cutadapt program [24], version 1.18. Reads shorter than $17 \mathrm{bp}$ after the trimming were removed from further analyses. The remaining reads were mapped to an E. huxleyi integrated reference transcriptome shortly described in [6] using the RSEM software [25], version 1.3.1, with the default option of bowtie, version 1.1.2 [26]. Genes that had at least 5 reads in any of the samples were selected. For the heatmap (Fig. 1d), read counts were scaled to one million reads mapped to the E. huxleyi transcriptome and $\log 2$ transformed. 


\section{Effect of vesicles on natural populations- experimental design and analysis}

On days 14 and 20 of the mesocosm experiment (blue and red arrows in Fig. 1a, respectively), we combined equal volumes of water samples from bags 1-4 and filtered them through a $10 \mu \mathrm{m}$ nylon mesh to eliminate zooplankton predators. We then supplemented the natural populations with $f / 50$ nutrient mix and divided them into flasks, each containing $10 \mathrm{ml}$. In total, 30 flasks were treated with vesicles from uninfected lab cultures of $E$. huxleyi CCMP2090, at a ratio of $\sim 500$ vesicles cell ${ }^{-1}$ (calcified $E$. huxleyi determined by flow cytometry), and then all flasks were incubated in a growth chamber $\left(15^{\circ} \mathrm{C}, 16: 8 \mathrm{~h}\right.$ light: dark cycle, $100 \mu \mathrm{mol}$ photons $\mathrm{m}^{-2} \mathrm{~s}^{-1}$ ). Once a day, samples were taken for flow cytometric quantification of live cells (see "Enumeration of phytoplankton cells by flow cytometry" above), or fixed for virus and bacteria counts (see "Enumeration of EhV-like particles and bacteria by flow cytometry" above). For statistical analysis, we used two-tailed $t$ test with equal variance.

\section{Decay rate of EhV virions- experimental design and analysis}

To determine the decay rate of infectivity of natural EhV virions, water was sampled from bag 4 on day 18, at a time point when viral infection was detected (green cross in Fig. 1a). This sample was filtered through a 0.45 PVDF filter (Durapore, Merck Millipore) to eliminate algal and most bacteria cells. EhV-like particles were counted by flow cytometry as described above and divided into nine tubes, each containing $1 \mathrm{ml}$. Triplicate samples were either treated with vesicles from EhV201-infected ( ${ }^{\text {Virus }}$ Vesicles) or uninfected ( ${ }^{\text {control }}$ Vesicles) lab cultures (see above) at a ratio of ten vesicles per EhV-like particle, or not treated at all. All tubes were incubated in an on-land mesocosm facility that mimics the light and temperature conditions found at $\sim 1 \mathrm{~m}$ depth within the fjord water. We used the most probable number (MPN) method [27] to determine the half-life of EhV within these samples. Briefly, a series of five-fold dilutions was prepared for each sample. Each dilution $(10 \mu \mathrm{l})$ was then added, in eight technical replicates, to $100 \mu \mathrm{l}$ of exponentially growing E. huxleyi CCMP374 cultures in multi-well plates and incubated under normal growth conditions for five days. This was repeated for four consecutive days for all samples. Clearance (infection) of the cells in the multi-wells was measured using an EnSpireTM 2300 Multilabel Reader (PerkinElmer, Turku, Finland) set to in vivo fluorescence (ex:460 nm, em:680 nm). MPN was calculated using the MPN calculation program, version 5 [28]. For the samples treated with ${ }^{\text {control }}$ vesicles, we could only obtain a positive MPN value for one time point, as the decay was faster than expected. Therefore, the minimum detectable infectivity values were used in order to calculate the maximum possible half-life. For statistical analysis, each treatment was compared to the untreated control, using ANOVA with Dunnett's post-hoc test.

\section{Data availability}

All the small RNA sequences were submitted to the SRA under BioProject PRJNA694552, accession SRR13648434 - SRR13648443.

Acknowledgements We thank all team members of the VIMS-Ehux project for setting up and conducting the mescosom experiment, especially Flora Vincent who performed the live flow cytometry counts on the mesocosm populations, Jorun Egge, Aud Larsen and Tatiana Tsagaraki. We are grateful to Ron Rotkopf for his advice on statistical analysis. A.V. is The Bronfman Professorial Chair of Plant Science. This research was supported by the European Research Council CoG (VIROCELLSPHERE grant no. 681715) and research grants from the Estate of Bernard Berkowitz and the de Botton Center for Marine Science awarded to AV. The mesocosm experiment VIMSEhux was supported by EU Horizon2020-INFRAIA project AQUACOSM (grant no. 731065).

Author contributions DS and AV conceptualized the project and wrote the manuscript. DS and GS designed and performed the experiments. MRS and R-AS performed the MPN analyses. EF performed all bioinformatic analyses on the RNA sequences. DS and GS extracted DNA and performed the qPCR analysis. All authors commented on the manuscript.

\section{Compliance with ethical standards}

Conflict of interest The authors declare no competing interests.

Publisher's note Springer Nature remains neutral with regard to jurisdictional claims in published maps and institutional affiliations.

Open Access This article is licensed under a Creative Commons Attribution 4.0 International License, which permits use, sharing, adaptation, distribution and reproduction in any medium or format, as long as you give appropriate credit to the original author(s) and the source, provide a link to the Creative Commons license, and indicate if changes were made. The images or other third party material in this article are included in the article's Creative Commons license, unless indicated otherwise in a credit line to the material. If material is not included in the article's Creative Commons license and your intended use is not permitted by statutory regulation or exceeds the permitted use, you will need to obtain permission directly from the copyright holder. To view a copy of this license, visit http://creativecommons. org/licenses/by/4.0/.

\section{References}

1. Rost B, Riebesell U. Coccolithophores and the biological pump: responses to environmental changes. In: Thierstein HR, Young JR, editors. Coccolithophores: from molecular processes to global impact. Berlin, Heidelberg: Springer Berlin Heidelberg; 2004. p. $99-125$. 
2. Tyrrell T, Merico A. Emiliania huxleyi: bloom observations and the conditions that induce them. In: Thierstein HR, Young JR, editors. Coccolithophores: from molecular processes to global impact. Berlin, Heidelberg: Springer Berlin Heidelberg; 2004. p. 75-97.

3. Bratbak G, Egge JK, Heldal M. Viral mortality of the marine alga Emiliania huxleyi (Haptophyceae) and termination of algal blooms. Mar Ecol Prog Ser. 1993;93:39-48.

4. Yáñez-Mó M, Siljander PRM, Andreu Z, Bedina Zavec A, Borràs FE, Buzas EI, et al. Biological properties of extracellular vesicles and their physiological functions. J Extracell Vesicles. 2015;4:27066.

5. Schatz D, Vardi A. Extracellular vesicles - new players in cell-cell communication in aquatic environments. Curr Opin Microbiol. 2018;43:148-54.

6. Schatz D, Rosenwasser S, Malitsky S, Wolf SG, Feldmesser E, Vardi A. Communication via extracellular vesicles enhances viral infection of a cosmopolitan alga. Nat Microbiol. 2017;2:1485-92.

7. Vardi A, Haramaty L, Van Mooy BAS, Fredricks HF, Kimmance SA, Larsen A, et al. Host-virus dynamics and subcellular controls of cell fate in a natural coccolithophore population. Proc Natl Acad Sci USA. 2012;109:19327-32.

8. Vincent F, Sheyn U, Porat Z, Schatz D, Vardi A. Visualizing active viral infection reveals diverse cell fates in synchronized algal bloom demise. Proc Natl Acad Sci USA. 2021;118: e2021586118.

9. Rosenwasser S, Mausz MA, Schatz D, Sheyn U, Malitsky S, Aharoni A, et al. Rewiring host lipid metabolism by large viruses determines the fate of Emiliania huxleyi, a bloom-forming alga in the ocean. Plant Cell. 2014;26:2689-707.

10. Barak-Gavish N, Frada MJ, Ku C, Lee PA, DiTullio GR, Malitsky $\mathrm{S}$, et al. Bacterial virulence against an oceanic bloom-forming phytoplankter is mediated by algal DMSP. Sci Adv. 2018;4: eaau5716.

11. McKew BA, Lefebvre SC, Achterberg EP, Metodieva G, Raines CA, Metodiev MV, et al. Plasticity in the proteome of Emiliania huxleyi CCMP 1516 to extremes of light is highly targeted. New Phytol. 2013;200:61-73.

12. Biller SJ, Schubotz F, Roggensack SE, Thompson AW, Summons RE, Chisholm SW. Bacterial vesicles in marine ecosystems. Science 2014;343:183-6.

13. Frada MJ, Rosenwasser S, Ben-Dor S, Shemi A, Sabanay H, Vardi A. Morphological switch to a resistant subpopulation in response to viral infection in the bloom-forming coccolithophore Emiliania huxleyi. PLoS Pathog. 2017;13:e1006775.
14. Mackinder LC, Worthy CA, Biggi G, Hall M, Ryan KP, Varsani A, et al. A unicellular algal virus, Emiliania huxleyi virus 86, exploits an animal-like infection strategy. J Gen Virol. 2009;90:2306-16.

15. Suttle CA. Viruses in the sea. Nature 2005;437:356-61.

16. Jacquet $\mathrm{S}$, Bratbak G. Effects of ultraviolet radiation on marine virus-phytoplankton interactions. FEMS Microbiol Ecol. 2003;44:279-89.

17. Suttle CA, Chen F. Mechanisms and rates of decay of marine viruses in seawater. Appl Environ Microbiol. 1992;58:3721-9.

18. Vincent F, Schleyer G, Kuhlisch C, Marrasé C, Simó R, Egge J, et al. AQUACOSM VIMS-Ehux - Core data. Dryad. 2020; https://doi.org/10.5061/dryad.q573n5tfr.

19. Sheyn U, Rosenwasser S, Ben-Dor S, Porat Z, Vardi A. Modulation of host ROS metabolism is essential for viral infection of a bloom-forming coccolithophore in the ocean. ISME J. 2016;10:1742-54.

20. Marie D, Simon N, Vaulot D. Phytoplankton cell counting by flow cytometry. In: Andersen RA, editor. Algal Culturing Techniques. Cambridge, USA: Academic Press; 2005. p. 253-67.

21. Brussaard CP. Optimization of procedures for counting viruses by flow cytometry. Appl Environ Microbiol. 2004;70:1506-13.

22. Sheyn U, Rosenwasser S, Lehahn Y, Barak-Gavish N, Rotkopf R, Bidle KD, et al. Expression profiling of host and virus during a coccolithophore bloom provides insights into the role of viral infection in promoting carbon export. ISME J. 2018;12:704-13.

23. Pagarete A, Allen MJ, Wilson WH, Kimmance SA, de Vargas C. Host-virus shift of the sphingolipid pathway along an Emiliania huxleyi bloom: survival of the fattest. Environ Microbiol. 2009;11:2840-8.

24. Martin M. Cutadapt removes adapter sequences from highthroughput sequencing reads. EMBnetjournal. 2011;17:3.

25. Li B, Dewey CN. RSEM: accurate transcript quantification from RNA-Seq data with or without a reference genome. BMC Bioinforma. 2011;12:323.

26. Langmead B, Trapnell C, Pop M, Salzberg SL. Ultrafast and memory-efficient alignment of short DNA sequences to the human genome. Genome Biol. 2009;10:R25.

27. Taylor J. The estimation of numbers of bacteria by tenfold dilution series. J Appl Bacteriol. 1962;25:54-61.

28. Jarvis B, Wilrich C, Wilrich PT. Reconsideration of the derivation of Most Probable Numbers, their standard deviations, confidence bounds and rarity values. J Appl Microbiol. 2010;109:1660-7. 